\title{
El proyecto del ferrocarril estratégico Ciudad Rodrigo a Río Tajo. Una infraestructura de principios de siglo XX no llevada a cabo
}

\author{
The strategic rail line Ciudad Rodrigo to Rio Tajo Project. An undrawn infrastruc- \\ ture of the beginning of the 2oth century
}

$\underline{\text { Pedro Plasencia-Lozano }}^{(*)}$

\section{RESUMEN}

El artículo analiza el proyecto del ferrocarril métrico Ciudad Rodrigo a Río Tajo, fechado en 1906. Pese a no llevarse a cabo, el documento es interesante porque ejemplifica la utilidad de los proyectos históricos no construidos como fuentes de datos para conocer el estado del arte de la ingeniería civil en su tiempo. El texto describe qué eran los denominados ferrocarriles estratégicos, analiza los principales parámetros técnicos usados: pendientes, radios de curva, secciones tipo; asimismo, recoge las variadas tipologías estructurales que se planteaban (incluyendo una de José Eugenio Ribera), analiza las principales edificaciones que se construían en las estaciones, muestra la introducción del tercer carril para compatibilizar dos anchos de vía distintos y expone el estudio de alternativas realizado para determinar el trazado idóneo.

Palabras clave: ferrocarriles estratégicos; patrimonio de la ingeniería; Fernando Govantes; José Eugenio Ribera; puentes.

\section{ABSTRACT}

The article analyzes the Ciudad Rodrigo to Río Tajo metric railway project, drawn in 19o6. Despite not being carried out, the document is interesting because it exemplifies the usefulness of historical unbuilt projects as data sources to know the state of the art of civil engineering in his time. The text describes what the so-called strategic railways were, analyzes the main technical parameters used: slopes, curve radius, type sections; furthermore, it shows the various structural typologies that are proposed (including one by José Eugenio Ribera), analyzes the main buildings that are built in the stations, goes over the introduction of the third rail to make two different track widths compatible and exposes the study of alternatives carried out to determine the ideal layout.

Keywords: strategic railway; engineering heritage; Fernando Govantes; José Eugenio Ribera; bridges.

(*) Dr. Ingeniero de Caminos, Canales y Puertos. Profesor. Universidad de Oviedo, Mieres (España)

Persona de contacto/Corresponding author: plasenciapedro@uniovi.es (P. Plasencia-Lozano)

ORCID: http://orcid.org/oooo-0oo1-5240-0733 (P. Plasencia-Lozano)

Cómo citar este artículo/Citation: Pedro Plasencia-Lozano (2021). El proyecto del ferrocarril estratégico Ciudad Rodrigo a Río Tajo. Una in-
fraestructura de principios de siglo XX no llevada a cabo. Informes de la Construcción, 73(563): e405. https://doi.org/10.3989/ic.79912

Copyright: (C) 2021 CSIC. Este es un artículo de acceso abierto distribuido bajo los términos de la licencia de uso y distribución Creative Commons Reconocimiento 4.0 Internacional (CC BY 4.0). 


\section{INTRODUCCIÓN}

Los proyectos de infraestructuras no construidos son una interesante fuente de datos sobre el estado de la técnica en el momento en que son concebidos. Estos proyectos nos ponen en relación con los parámetros técnicos de la traza, con las alternativas en cuanto al trazado óptimo, con las tipologías estructurales, con los túneles, con aspectos de la explotación económica y empresarial, con los precios de materiales de obra y también ferroviarios, con los métodos de cálculo o con la configuración de las estaciones. Hoy día, al estudiar uno de tantos documentos técnicos que no fueron ejecutados, cabe lamentarse por el hecho de que el trabajo vertido en él por parte del proyectista no se viera plasmado sobre el territorio; esta sensación aumenta cuando intuimos las potenciales ventajas que la construcción de un proyecto podía haber generado en la región donde se proyectó, y observamos la escasez de infraestructuras que existe hoy día en la misma. Acaso la historia de un determinado territorio hubiera sido muy diferente si se hubieran llevado a cabo todos los proyectos ferroviarios concebidos pero no proyectados a lo largo de los siglos. Además, estos documentos son sumamente interesantes porque ofrecen una realidad del estado de la técnica en su momento; asimismo, los proyectos ferroviarios de la época eran un auténtico documento técnico y empresarial, que debían justificar su viabilidad económica y por ello contenían información valiosa sobre aspectos sociales y empresariales de los territorios atravesados.

Este artículo aporta luz a todas las cuestiones citadas en relación con un ferrocarril proyectado en 1906, el proyecto de la línea Ciudad Rodrigo (Salamanca) a Río Tajo (Cáceres) (figura 1). La investigación ha tomado como base diversos documentos existentes en el Archivo General de la Administración (AGA 24-09922, AGA 24-09928); también se han consultado artículos y textos relacionados con la técnica de la época. En él se estudia el origen del proyecto y su traza; a continuación se analizan las estructuras, las estaciones y otros edificios accesorios; además se describe un proyecto modificado. Finalmente, se sintetizan una serie de conclusiones.

\section{ORIGEN DEL PROYECTO. LOS FERROCARRI- LES SECUNDARIOS Y ESTRATÉGICOS}

Si bien existe el precedente de un proyecto ferroviario en la misma zona auspiciado por el ingeniero Darío Bacas y la Sociedad Extremeño Castellana (1), el proyecto aquí referido tiene origen en la Ley de Ferrocarriles Secundarios y Estratégicos de 26 de mayo de 1908 que impulsaba la construcción de dos tipos de infraestructuras ferroviarias, las líneas secundarias y las estratégicas. Las secundarias estaban "destinadas al servicio público con motor mecánico de cualquier clase que (...) no estén comprendidos en la red de los de servicio general, tal como se halla definida y establecida en el capítulo $1^{\circ}$ de la Ley de 23 de noviembre de 1877"; asimismo, las estratégicas eran "aquellas que, con independencia del servicio que presten a otros intereses generales, atiendan directamente a necesidades o conveniencias de la defensa nacional". Una de las singularidades de los estratégicos era que los consejos de administración de las compañías impulsoras de estas líneas debían estar compuestos por ciudadanos españoles con residencia en España, requisito no exigido para las compañías de secundarios, que sí debían tener al menos la sede social en el país; esta particularidad acentuaba el carácter castrense de los ferrocarriles estratégicos en caso de confrontación con otro estado.

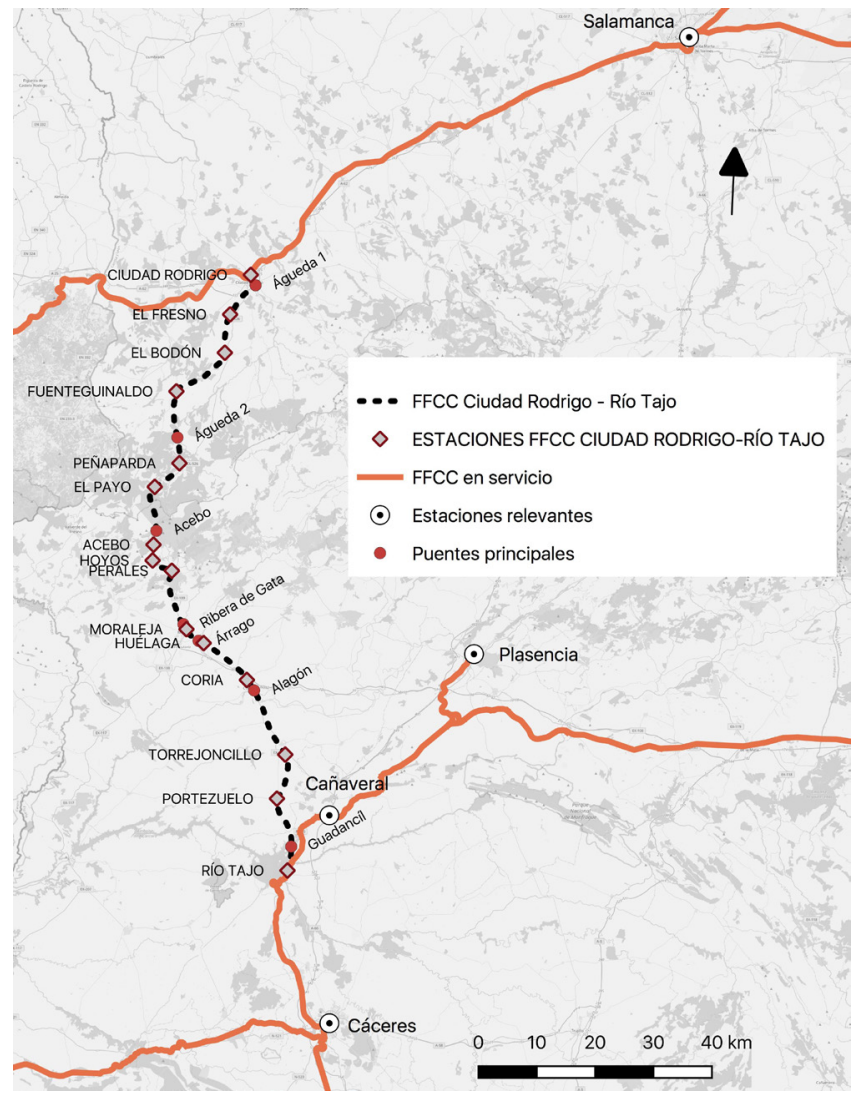

Figura 1. Situación del ferrocarril Ciudad Rodrigo a Río Tajo; se incluye la ubicación de las principales estructuras

Esta ley se inspiró en otras europeas, particularmente en la francesa, según un estudio realizado por Cambó (2); aunque el propio Cambó apuntaba que el concepto de ferrocarril estratégico, "por la forma y lugar en que se expresa, es absolutamente privativo de la legislación española, sin que en ninguna de las extranjeras se encuentre nada análogo" (3). Sí había ferrocarriles de carácter vecinal en Bélgica, de interés local en Francia, locales en Alemania, y secundarios en Suecia, Islas Británicas, o Austria-Hungría, pero no de carácter estratégico

En relación con el procedimiento para la construcción y posterior explotación de la línea, apuntamos que la Ley definía una lista de itinerarios. El gobierno promovía una licitación para cada una de las líneas, y las empresas interesadas presentaban un proyecto de construcción y explotación. Las propuestas eran evaluadas y finalmente se elegía una, si bien durante la tramitación podían incluirse modificaciones del proyecto elegido.

Cuatro años después de la publicación de la ley, en la Gaceta de 29 de agosto de 1912, se publicaron las condiciones para el concurso del proyecto del ferrocarril estratégico de Ciudad Rodrigo a Río Tajo, dando un plazo de cinco meses para presentar propuestas. A este concurso se presentaron dos proyectos, uno el 28 de enero de 1913 del ingeniero Epifanio Barco, siendo peticionarios Clemente Oria y Emilio Pérez, y otro el 29 del mismo mes suscrito por Fernando Govantes, siendo peticionarios Benigno Gallego y el propio Govantes (figura 2). Recibidos en el Ministerio, los proyectos fueron estudiados por el ingeniero Feliciano Navarro. El proyecto Govantes fue considerado como "muy válido", aunque Navarro introduciría ligeras modificaciones que se analizan en 


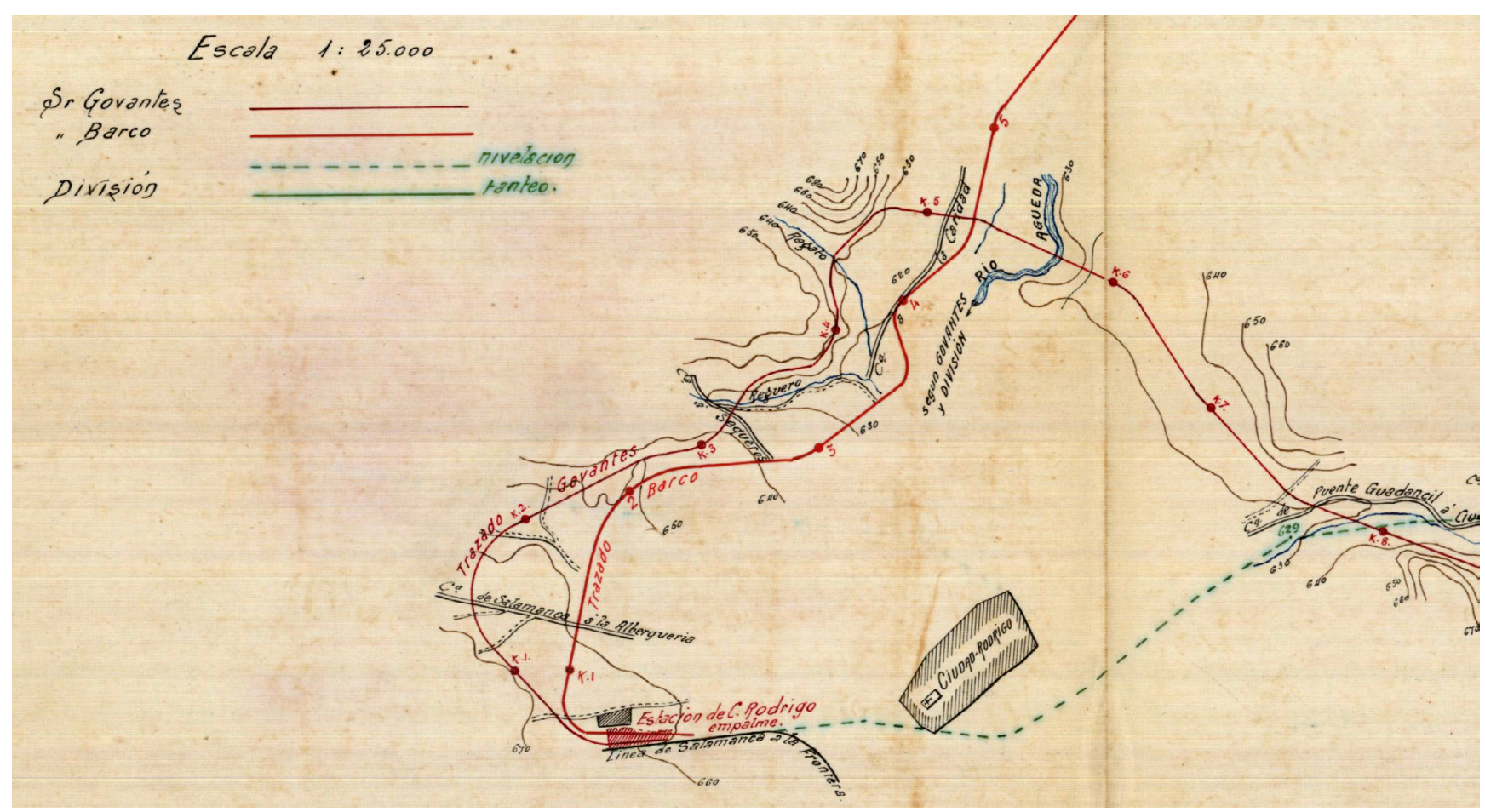

Figura 2. Estudio comparado de los dos itinerarios en las inmediaciones de Ciudad Rodrigo realizado por Feliciano Navarro

un apartado posterior de este texto. En cuanto al proyecto de Barco, fue desechado al incurrir en diversos errores, como proponer una variante por Gata que era inadmisible por las bases del concurso.

El proyecto Govantes cumplía con lo definido en el artículo 33 de la Ley de Ferrocarriles Secundarios y Estratégicos, que entre otras cuestiones, señalaba lo siguiente:

- La velocidad comercial mínima, para un tren cargado, será de $25 \mathrm{~km} / \mathrm{h}$.

- El ancho de la vía será de un metro.

- La línea enlazará con todas las que concurren a puntos servidos por la misma, entendiéndose por enlaces entre líneas de distinto ancho de vía el que ambas concurran a un muelle común que facilite los transbordos.

- Por regla general las pendientes no deberán exceder de 20 milésimas, y el radio de las curvas no bajará de $120 \mathrm{~m}$, admitiéndose excepciones a estas reglas únicamente en casos muy justificados.

- El peso del carril no será inferior a $30 \mathrm{~kg} / \mathrm{m}$, y en las rampas de gran longitud, con inclinaciones de 15 a 20 milésimas, se empleará al menos el de $35 \mathrm{~kg} / \mathrm{m}$.

Había además algunos aspectos que reforzaban la idea de que el ferrocarril era estratégico por su interés militar:

- Se procurará que la vía, y singularmente las obras de fábrica, estaciones, depósitos de material y talleres, estén a cubierto o desenfiladas de las fortificaciones del país vecino o de las alturas o puntos situados en él que el enemigo pudiera ocupar para destruir la línea o para estorbar su utilización.

- El ferrocarril deberá hallarse dotado de material apropiado para el transporte de piezas de artillería de $4.500 \mathrm{~kg}$ de peso máximo indivisible y de 4,20 $\mathrm{m}$ de largo en su mayor dimensión.
- No deberá trazarse la línea a vanguardia de los puntos fortificados ni de aquellas posiciones que por su situación o condiciones especiales hayan de ocuparse y constituir núcleos de la defensa o apoyos del ataque en caso de guerra. Para el cumplimiento de esta prescripción y de la anterior, el Ministerio de la Guerra, facilitará a los peticionarios, estudios y nota de los puntos principales de paso.

- Los proyectos serán firmados por facultativos competentes con título expedido en España.

- Queda prohibido para este ferrocarril el aprovechamiento de carreteras u otras vías ordinarias, permitiéndose sólo el cruzamiento de las mismas en las mejores condiciones posibles, y en casos muy especiales y justificados podrán aprovecharse obras de carreteras en determinados pasos.

\section{DESCRIPCIÓN DEL PROYECTO GOVANTES}

En la Memoria se alude a la dificultad de recorrer un terreno abrupto, salvando la divisoria de las cuencas de los ríos Duero y Tajo, cruzando la Sierra de Gata y los empinados barrancos de sus estribaciones (figura 3). Se señala que la construcción de la línea constituía una necesidad general de la Nación, y como tal había sido reconocido por la Junta Suprema de Defensa Nacional, que lo había incluido entre los ferrocarriles estratégicos, por su valor militar. Este ferrocarril permitiría unir dos líneas radiales de primer orden, la de Medina a Salamanca y Ciudad Rodrigo, y la que va desde Madrid a Portugal pasando por Plasencia. Era así una línea de maniobras de gran valor, ya que permitía “concentrar rápidamente personal y material de guerra sobre la frontera para vigilarla, defenderla o invadirla”. Además, en esa parte de la frontera existía en Portugal una línea sensiblemente paralela, de 213 $\mathrm{km}$ y de ancho normal, entre Guarda y Sabugal a Abrantes, pasando Covilha y Castelo Branco. Por ello, se recomendaba que esta línea propuesta tuviera "una capacidad o potencia 


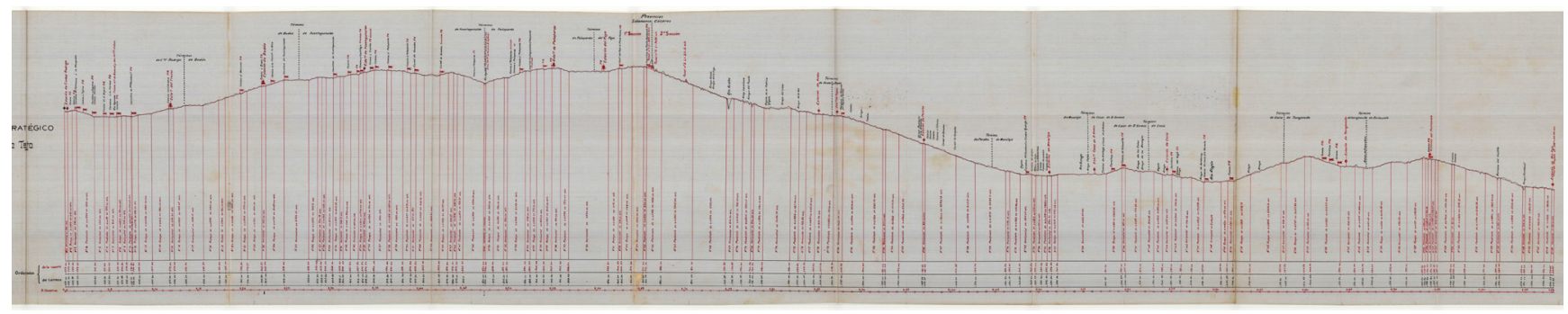

Figura 3. Perfil del trazado propuesto

de transporte casi igual a las líneas de ancho normal”. Esto se podía conseguir con un buen trazado, una vía reforzada, máquinas poderosas y material articulado.

El proyecto propone la construcción del ferrocarril de "Ciudad Rodrigo por Hoyos, Coria y Torrejoncillo a la estación de Río Tajo, en el ferrocarril de Malpartida de Plasencia a Cáceres"; se preveían un total de 15 estaciones, de norte a sur: Ciudad Rodrigo, El Fresno, El Bodón, Fuenteguinaldo, Peñaparda, El Payo, Acebo, Hoyos, Perales, Moraleja, Huélaga, Coria, Torrejoncillo, Portezuelo y Río Tajo.

La Memoria apunta que "los factores de riqueza que pueden proporcionar vida a un ferrocarril son muchos", y enumera un total de siete parámetros: densidad de población, riqueza agrícola, riqueza forestal, riqueza pecuaria, riqueza minera, riqueza de materiales de construcción y riqueza industrial; según Govantes, es suficiente que "abunden dos o tres de esas clases de riquezas para que el ferrocarril tenga vida desahogada". El texto considera con cierto entusiasmo que el ferrocarril era viable a la vista de las consideraciones vertidas sobre esos siete parámetros. En cuanto a la densidad de población, las comarcas atravesadas tenían una densidad baja, $20 \mathrm{hab} / \mathrm{km}^{2}$ en Cáceres y unos $27 \mathrm{hab} / \mathrm{km}^{2}$ en las regiones salmantinas; sin embargo se indicaba la existencia de pueblos de bastante importancia a lo largo del trazado, y se estimaba que en la zona de influencia del mismo, establecida en $14 \mathrm{~km}$ alrededor de cada estación, habitaban unas 76.318 personas.

Del mismo modo, se consideraba que la riqueza agrícola del entorno era muy relevante haciendo hincapié en que los limones y naranjas del Tajo competían con los valencianos,; la riqueza forestal era abundante, y la pecuaria era de gran importancia. En lo referente a las riquezas mineras e industriales, Govantes aducía que estaban poco desarrolladas precisamente por la falta de vías de comunicación; así, en la provincia de Cáceres se cifraban 214 minas, pero sólo 11 eran productivas; en Salamanca había 104 minas (cobre, estaño, hierro, topacio, plomo, wolframio), siendo muy pocas productivas, y el ingeniero afirmaba que la construcción del ferrocarril haría rentable su explotación.

Una de las cuestiones sorprendentes de este trazado es la elección de la estación de Río Tajo como punto final de la línea (figura 4). La propia Memoria llama la atención sobre este hecho, señalando que "atendiendo a los escasos medios que integran la actual estación no se concibe ni se acierta a comprender las razones que tuvo la Superioridad para ordenar que el enlace del ferrocarril estratégico que estudiamos sea en Rio Tajo, sito despoblado y sin recursos, y no la estación anterior, Cañaveral, que cuenta con muchos más medios y con una población de 2.418 habitantes". Tal vez el motivo radicase en que el tramo siguiente de los ferrocarriles econó- micos debía partir de la última estación de la línea que estamos analizando para enlazar con Alcántara, hacia el oeste; Cañaveral se encuentra al este de Río Tajo, por lo que una línea Cañaveral-Alcántara hubiera sido considerablemente más larga que el itinerario Río Tajo-Alcántara.

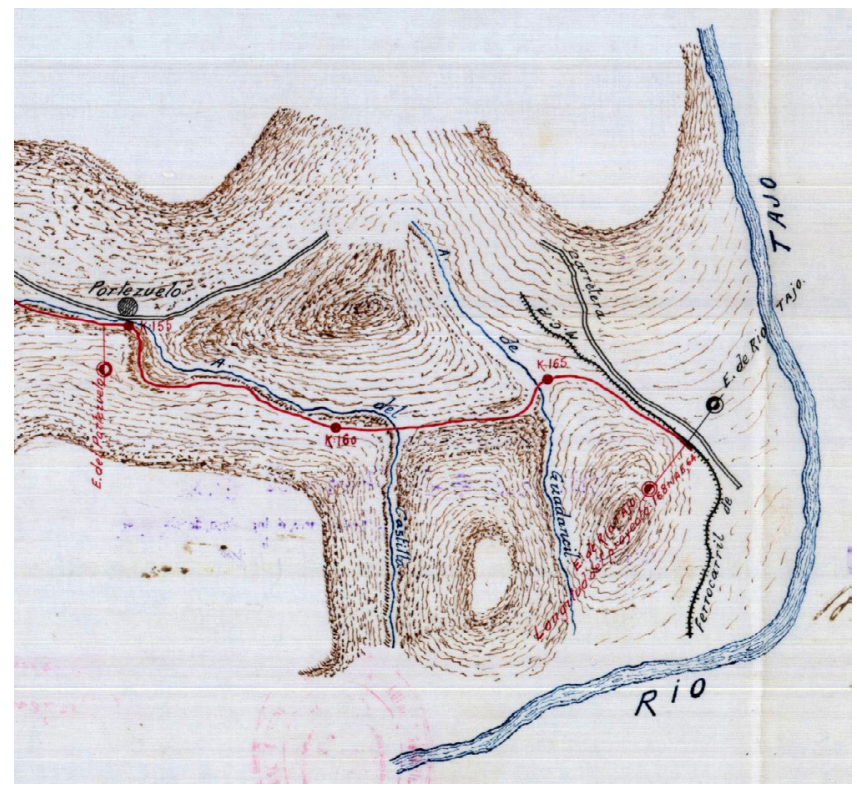

Figura 4. Entorno de la estación de Río Tajo), final de la línea

\subsection{Alternativas}

La principal dificultad orográfica de la zona es el paso de las sierras de Gata y Jalama, que divide las cuencas de los ríos Duero y Tajo. Las condiciones previas del proyecto exigían que el trazado pasara por Ciudad Rodrigo y por Hoyos, y el proyecto analizó hasta siete posibles alternativas para definir el itinerario (tabla 1, figura 5). Resulta interesante comprobar los parámetros principales empleados para ello: las distancias a ambas poblaciones, las distancias a recorrer con rampas más desfavorables, y los posibles túneles; nada se indica sin embargo sobre el impacto ambiental de la construcción de la línea, un parámetro fundamental en los estudios de alternativas actuales.

La alternativa por Perales resultaba ser la idónea. El parámetro de longitud era el más adecuado $(51 \mathrm{~km}$, el recorrido más corto); además la cota máxima era la menor de todas ellas (941 m sobre el nivel del mar); finalmente, la longitud de la rampa necesaria, a la vista del trazado, era también inferior al resto de trazados.

Otro parámetro determinante en estos estudios es la necesidad o no de construir túneles; varias de las alternativas requerían al menos uno, porque la sierra de Gata tiene pendientes 
Tabla 1. Resumen de distancias y desniveles de las siete alternativas, en la vertiente norte de cada puerto (lado CR) y sur (lado H). Cota de Hoyos: $569 \mathrm{~m}$; cota de CR: $659 \mathrm{~m}$

\begin{tabular}{|c|c|c|c|c|c|c|c|c|c|c|}
\hline : & 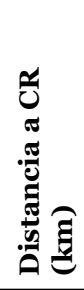 & 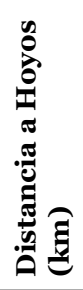 & $\underset{E}{E}$ & 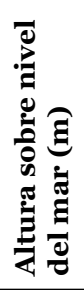 & 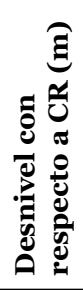 & 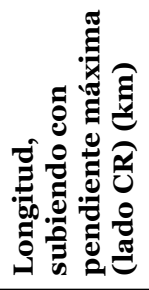 & 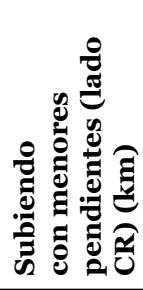 & 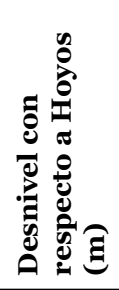 & 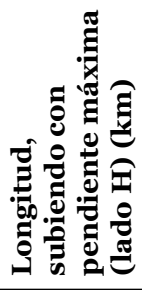 & 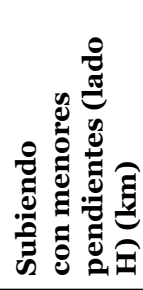 \\
\hline San Miguel & 44,2 & 12,0 & 56,2 & 1093 & 434 & 21,7 & 30,38 & 534 & 26,7 & 37,38 \\
\hline Villamiel & 41,4 & 11,0 & 52,4 & 1048 & 389 & 19,45 & 27,23 & 479 & 23,95 & 32,975 \\
\hline Acebo & 41,6 & 9,5 & 51,1 & 1010 & 361 & 18,05 & 25,27 & 451 & 22,55 & 31,57 \\
\hline Perales & 41 & 10,0 & 51,0 & 941 & 282 & 14,125 & 23,7 & 372 & 18,625 & 27,075 \\
\hline Gata & 38,4 & 15,0 & 53,4 & 1265 & 606 & 31,3 & 42,42 & 696 & 34,8 & 48,72 \\
\hline Descargamaría & 31,6 & 24,7 & 56,3 & 990 & 341 & 17,05 & 23,87 & 421 & 21,05 & 29,47 \\
\hline Robledillo & 29,2 & 28,6 & 57,8 & 1238 & 579 & 28,95 & 40,53 & 669 & 33,45 & 46,83 \\
\hline
\end{tabular}

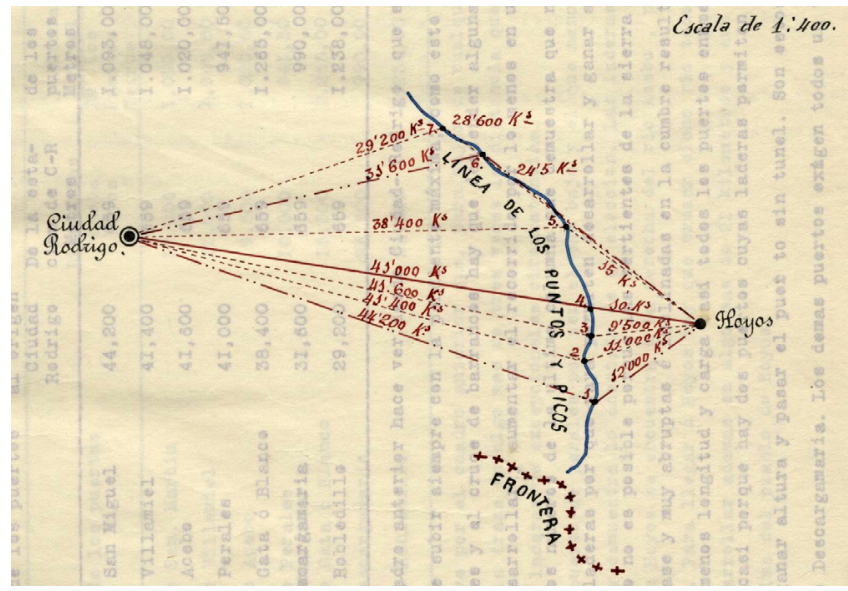

Figura 5. Imagen de las alternativas pensadas para el paso por la Sierra de Gata. La alternativa elegida fue la número 4

muy tendidas y de poca inclinación relativa en su base, y muy abruptas e inclinadas en la cumbre. Sólo evitarían esta obra las alternativas de Descargamaría y San Martín, pero fueron desechadas: San Martín por transcurrir muy próximo a la frontera, y Descargamaría porque obligaría a cruzar varias veces el río Acebo. Es por ello que, pese a existir dos opciones que no precisaban construir túnel, se optó por la alternativa $\mathrm{n}^{\mathrm{0}} 4$, Perales.

Un problema derivado de los continuos desniveles es la afección generada en las comunicaciones. En la Memoria, por ello, se cita que sería la "respetable casa Marconi Wireless Telegraph, Lth." quien resolviera los eventuales problemas instalando un sistema de telegrafía sin hilos.

\subsection{Planteamiento de las obras}

El trazado está dividido en dos secciones. La primera, correspondiente al itinerario por la provincia de Salamanca, tiene $66,28 \mathrm{~km}$; la segunda discurre ya por Cáceres, y alcanza una longitud de $91,865 \mathrm{~km}$. Estas secciones son divididas en trozos que oscilan entre los 18 y los 28 km (tabla 2); la división se realiza siempre entre estaciones. Se preveía que la construcción se llevara a cabo en cinco años, y se consideraba oportuno iniciar los trabajos en dos o más puntos a la vez de cada trozo.
Tabla 2. División en secciones y trozos

\begin{tabular}{|c|c|c|c|}
\hline Sección & Trozo & PK & Longitud (km) \\
\hline \multirow{3}{*}{ 1 (Salamanca) } & 1 & 0+000 a $22+750$ & 22,750 \\
\cline { 2 - 4 } & 2 & $22+750$ a $47+455$ & 24,705 \\
\cline { 2 - 4 } & 3 & $47+455$ a $66+280$ & 18,825 \\
\hline \multirow{3}{*}{ 2 (Cáceres) } & 1 & $66+280$ a $88+585$ & 22,305 \\
\cline { 2 - 4 } & 2 & $88+585$ a $116+398$ & 27,813 \\
\cline { 2 - 4 } & 3 & $116+398$ a $144+873$ & 28,475 \\
\cline { 2 - 4 } & 4 & $144+873$ a $168+145$ & 23,272 \\
\hline
\end{tabular}

\section{3•3. Características técnicas}

Los parámetros de trazado fundamentales en las obras ferroviarias son el radio de curva mínimo y la rampa máxima. El proyecto plantea 15 curvas de radio $120 \mathrm{~m}$ y rampas de máximo 20 milésimas. Además, los cambios de rasante se proyectan de forma que coincidan siempre en alineaciones rectas. Por último, se establece la regla de disponer una recta de al menos $100 \mathrm{~m}$ de longitud entre dos curvas contiguas de diferente sentido. Para los acuerdos, se escogen las curvas ideadas por Wilhelm Nordling (4).

Tabla 3. Disposición de traviesas

\begin{tabular}{|l|c|c|}
\hline \multicolumn{1}{|c|}{ Tipo } & $\begin{array}{c}\text { Traviesas } \\
\text { por carril }\end{array}$ & $\begin{array}{c}\text { Distancia entre } \\
\text { traviesas }\end{array}$ \\
\hline Recta o curva con $\mathrm{R}>800 \mathrm{~m}$ & 10 & Cada $0,836 \mathrm{~m}$ \\
\hline Curva con $800 \mathrm{~m}>\mathrm{R}>400 \mathrm{~m}$ & 11 & Cada $0,750 \mathrm{~m}$ \\
\hline Curva con $\mathrm{R} \leq 400 \mathrm{~m}$ & 12 & Cada $0,682 \mathrm{~m}$ \\
\hline
\end{tabular}

En cuanto a la sección tipo (figura 6), la explanada sobre la que se dispone el balasto debe tener una anchura de $4 \mathrm{~m}, \mathrm{y}$ se define que la capa de balasto presente un talud $1 / 1$; con respecto a la anchura, se exige que dicha capa tenga, a mitad de altura, la anchura del material móvil previsto (2,50 m). El carril adoptado es de $35 \mathrm{~kg} / \mathrm{m}$; cada uno de ellos alcanza una longitud de $8 \mathrm{~m}$, apoyado en un número variable de traviesas (tabla 3) de roble o pino, creosotadas, con dimensiones 1,80 $\mathrm{m}$ de largo, 0,22 de tabla y o,14 de canto. El ancho de la vía es de $1 \mathrm{~m}$, y se establecen unos sobreanchos en las curvas más cerradas (tabla 4). 


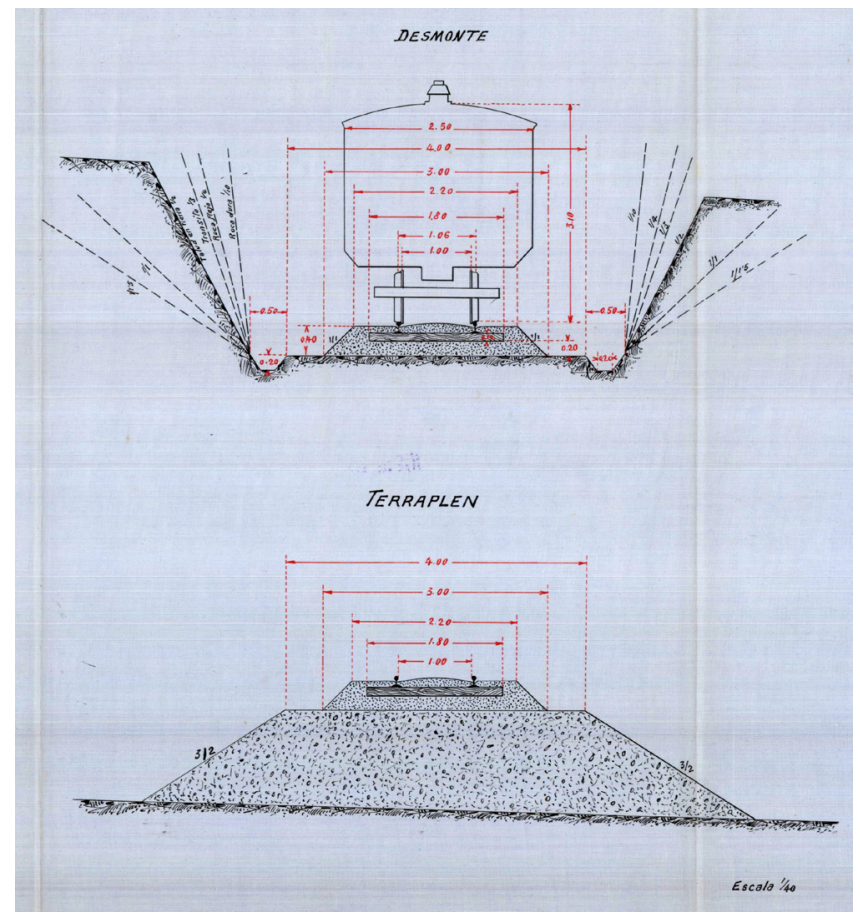

Figura 6. Secciones tipo previstas

La Memoria indica que el carril de $35 \mathrm{~kg} / \mathrm{m}$ era poco usual, incluso en ancho de vía normal (cuyo material móvil pesaba más). En esa fecha, la Compañía del Norte y la de Madrid a Zaragoza y a Alicante tenían, en algunos trayectos de ancho ibérico, carriles de $42 \mathrm{~kg} / \mathrm{m}$, pero el resto de la red ferroviaria española se componía de carriles de 28 y $32,5 \mathrm{~kg} / \mathrm{m}$. En estos cálculos se considera que las locomotoras previstas tendrían un peso en vacío de $40.000 \mathrm{~kg}$, y de $45.000 \mathrm{~kg}$ en carga, y la rueda más cargada alcanzaría los $6.000 \mathrm{~kg}$. Si bien cabía la opción de adoptar la tracción eléctrica (artículo 33 de la Ley de Ferrocarriles), se opta por un ferrocarril a vapor, siendo $483 \mathrm{cv}$ la potencia desarrollada por la locomotora de proyecto (figura 7 ).

En relación con los parámetros descritos, pueden establecerse comparaciones con otros ferrocarriles métricos. Así, por ejemplo, el ferrocarril Peñarroya-Fuente del Arco, cuyo proyecto modificado data de 1894, establece un radio mínimo de $200 \mathrm{~m}$ y una pendiente máxima de 20 milésimas. Sin embargo, la plataforma es menor que la aquí citada, pues alcanza los 3 m (5).

Tabla 4. Sobreanchos

\begin{tabular}{|l|c|}
\hline Tipo & Anchura \\
\hline Curvas con radio 100 a $150 \mathrm{~m}$ & $1,02 \mathrm{~m}$ \\
\hline Curvas con radio 160 a $300 \mathrm{~m}$ & $1,15 \mathrm{~m}$ \\
\hline Curvas con radio 300 a $450 \mathrm{~m}$ & $1,01 \mathrm{~m}$ \\
\hline
\end{tabular}

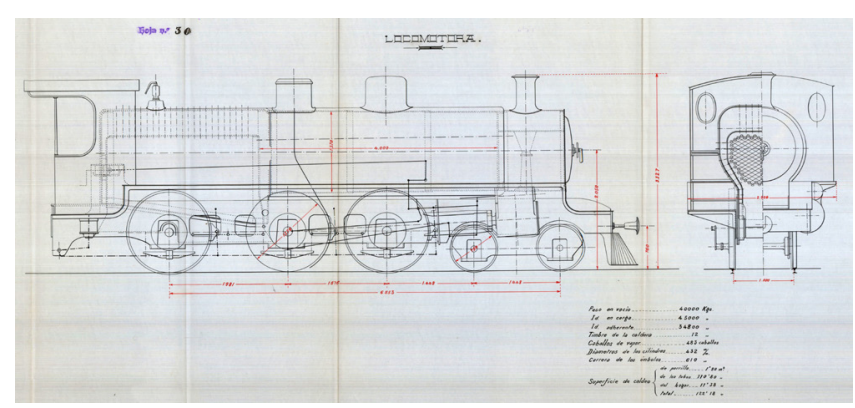

Figura 7. Locomotora de proyecto.

\subsection{Presupuesto}

El Presupuesto del proyecto determina los precios de todas las unidades de obra; los principales capítulos (tabla 5) son los de explanación, vía, material móvil y obras especiales. Para realizarlo Govantes tomó precios de obras de reciente construcción, como el ferrocarril Tajuña-Orense.

Tabla 5. Resumen del presupuesto

\begin{tabular}{|l|r|r|}
\hline \multicolumn{1}{|c|}{ Capítulo } & \multicolumn{1}{c|}{$\begin{array}{c}\text { Totales } \\
\text { (pesetas) }\end{array}$} & $\begin{array}{c}\text { Precio por } \\
\text { km (pesetas) }\end{array}$ \\
\hline Expropiación & $1.461 .724,07$ & $8.693,20$ \\
\hline Explanación & $14.122 .194,08$ & $83.987,87$ \\
\hline Obras de fábrica & $1.874 .651,03$ & $11.148,97$ \\
\hline Obras especiales & $2.415 .479,03$ & $14.365,39$ \\
\hline Túneles & $723.766,19$ & 430,44 \\
\hline Estaciones & $1.317 .865,69$ & $7.837,64$ \\
\hline Casillas de guarda & $314.472,24$ & $1.870,28$ \\
\hline Vía & $9.445 .918,21$ & $56.177,00$ \\
\hline Material fijo de estaciones & $458.000,00$ & $2.723,82$ \\
\hline Pasos a nivel & $54.390,00$ & 323,47 \\
\hline Material móvil & $2.864 .850,00$ & $17.037,91$ \\
\hline Accesorios generales & $126.460,00$ & 752,08 \\
\hline Teléfono & $142.660,00$ & 848,43 \\
\hline & $35.322 .430,54$ & $210.070,45$ \\
\hline $\begin{array}{l}\text { 8\%: Imprevistos (1\%), acciden- } \\
\text { tes (2\%) y administración }(5 \%)\end{array}$ & $2.825 .794,44$ & \\
\hline Totales & $38.148 .224,98$ & $226.876,08$ \\
\hline
\end{tabular}

El coste del proyecto, 226.876,08 pesetas $/ \mathrm{km}$, es considerado adecuado por Govantes; en la Memoria escribe que la línea San Sebastian-Hernani costó 345.121,75 pesetas $/ \mathrm{km}$, y que la Cartagena-Descargador llegó a 342.334,58 pesetas $/ \mathrm{km}$. también se indica que los autores franceses, como G. Humbert, cifraban en 75.000 francos $/ \mathrm{km}(80.302,5$ pesetas $/ \mathrm{km}$ ) el coste de las nuevas líneas métricas en Francia, pero en un país llano y con carriles de $18 \mathrm{~kg} / \mathrm{m}$; además, la línea de Saint-Georges d'Commiers a La Mure (Isere) alcanzaba los 360.000 francos $/ \mathrm{km}(385.452$ pesetas $/ \mathrm{km})$, y los ferrocarriles de Córcega se construían por 250.000 francos el $\mathrm{km}$ (267.675 pesetas/km) (6).

Tabla 6. Tarifas previstas

\begin{tabular}{|l|c|l|c|}
\hline & $\begin{array}{c}\text { Pesetas por } \\
\text { viajero y km }\end{array}$ & $\begin{array}{c}\text { Pesetas por } \\
\text { tonelada y km }\end{array}$ \\
\hline Viajeros $1^{\mathrm{a}}$ & 0,100 & ${\text { Mercancías } 1^{\mathrm{a}}}^{\mathrm{a}}$ & 0,35 \\
\hline${\text { Viajeros } 2^{\mathrm{a}}}^{\mathrm{a}}$ & 0,075 & ${\text { Mercancías } 2^{\mathrm{a}}}^{\mathrm{a}}$ & 0,30 \\
\hline${\text { Viajeros } 3^{\mathrm{a}}}$ & 0,055 & ${\text { Mercancías } 3^{\mathrm{a}}}$ & 0,25 \\
\hline
\end{tabular}

El proyecto realiza un cálculo de la viabilidad económica de la línea ferroviaria; para ello era necesario determinar las tarifas, y Govantes propone emplear las del proyecto de ferrocarril económico de Guernica a Luno, Mundaca y Bermeo, redactado por el ingeniero Landeche (tabla 6). Este ferrocarril, aduce Govantes, presentaba unas tarifas más económicas que otros como el de Manzanares a Córdoba, Lérida a Reus y Tarragona, o Villena a Alcoy. Otro dato necesario es el de los usuarios previstos; para ello se utiliza el promedio de viajeros que circularon en 1907 en los ferro- 
Tabla 7. Material móvil previsto

\begin{tabular}{|c|c|c|c|}
\hline & Uds. & $\begin{array}{c}\text { Coste unitario } \\
\text { (pesetas) }\end{array}$ & $\begin{array}{c}\text { Coste total } \\
\text { (pesetas) }\end{array}$ \\
\hline $\begin{array}{l}\text { Locomotora con su } \\
\text { ténder }\end{array}$ & 15 & 90.000 & 1.350 .000 \\
\hline $\begin{array}{l}\text { Coche mixto de } 1^{\mathrm{a}}, 2^{\mathrm{a}} \\
{\mathrm{y} 3^{\mathrm{a}}}\end{array}$ & 8 & 23.500 & 188.000 \\
\hline Coche mixto de $1^{\mathrm{a}}$ y $2^{\mathrm{a}}$ & 8 & 25.000 & 200.000 \\
\hline Coche de $3^{\mathrm{a}}$ clase & 12 & 21.000 & 252.000 \\
\hline Coche de $2^{\mathrm{a}}$ clase & 1 & 22.500 & 22.500 \\
\hline Coche salón & 1 & 28.000 & 28.000 \\
\hline Furgón coche correos & 3 & 12.500 & 37.500 \\
\hline Furgón de carga & 21 & 5.300 & 111.300 \\
\hline Vagón cerrado grande & 8 & 8.500 & 68.000 \\
\hline $\begin{array}{l}\text { Vagón cerrado } \\
\text { pequeño }\end{array}$ & 15 & 3.570 & 53.550 \\
\hline Borde alto grande & 15 & 8.000 & 120.000 \\
\hline Borde algo pequeño & 30 & 2.800 & 84.000 \\
\hline Borde bajo grande & 20 & 7.500 & 150.000 \\
\hline Borde bajo pequeño & 30 & 2.500 & 75.000 \\
\hline Plataforma grande & 8 & 7.000 & 56.000 \\
\hline Plataforma pequeña & 8 & 2.500 & 20.000 \\
\hline Jaula para ganado & 8 & 3.500 & 28.000 \\
\hline Vagón de socorro & 2 & 4.000 & 8.000 \\
\hline Vagón grúa & 1 & 13.000 & 13.000 \\
\hline Total & & & 2.864 .850 \\
\hline
\end{tabular}

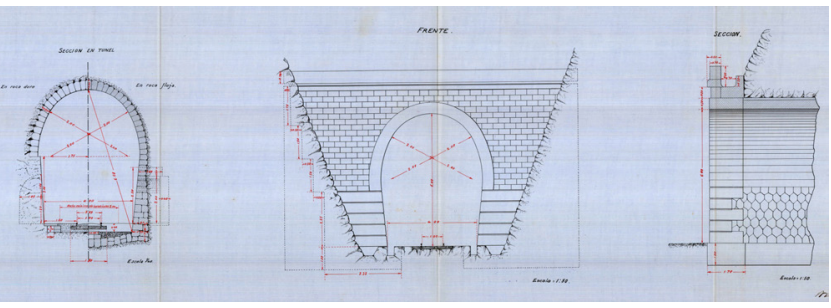

Figura 8. Secciones de túnel y embocaduras

carriles de vía estrecha de España: un 8,37\% en primera, un $24,67 \%$ en segunda y un $66,96 \%$ en tercera. En cuanto a la circulación de la línea, se prevén 4 trenes diarios de viajeros ( 2 correos y 2 mixtos), más 8 de mercancías, y dos expresos semanales. En total, 86 trenes por semana. Con ello se determinan las necesidades del material móvil a adquirir (tabla 7).

\section{ESTRUCTURAS Y TÚNELES}

El trazado proyectado incluye la construcción de siete estructuras de gran relevancia y tres túneles (tabla 8). Estas obras son las de mayor complejidad técnica dentro de las comprendidas en el proyecto. Para los túneles Govantes decide adoptar la sección preconizada por G. Humbert en el Traité des chemins de fer d'interet local (figura 8). En el caso de las estructuras, las diversas tipologías empleadas responden al estado del arte de la ingeniería del momento, que empleaba soluciones diversas en función de la luz a resolver y la economía de construcción. Además de las obras principales, el proyecto incluye modelos de tajeas, alcantarillas o pontones de hasta $6 \mathrm{~m}$ de luz.

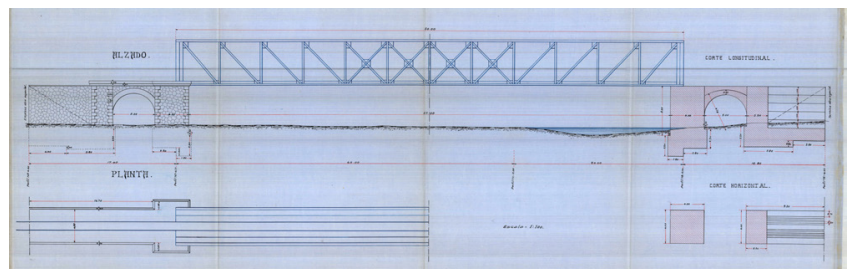

Figura 9. Puente sobre el río Águeda 1

El puente Águeda 1 (figura 9) está formado por tres vanos, uno central metálico y los dos extremos de hormigón revestido. El vano central se resuelve mediante una celosía de acero de tipo Pratt de $60 \mathrm{~m}$ de largo para salvar una luz de $57 \mathrm{~m}$. El canto alcanza los $6 \mathrm{~m}$, con montantes dispuestos cada $5 \mathrm{~m}$; la anchura de $4 \mathrm{~m}$ permite incluir dos pasarelas laterales a la vía. Las distintas partes de la celosía se forman mediante láminas que se añaden para lograr un espesor mínimo, y que se unen posteriormente con roblones; estas láminas tienen espesores de 10, 15 y $20 \mathrm{~mm}$, y de 8, 12 y $20 \mathrm{~mm}$ las angulares. En cuanto a los arcos laterales, presentan una luz de 5 $\mathrm{m}$. El cálculo del espesor de la clave se realiza conforme a la fórmula de Sejourné, muy usada en cálculos de puentes sobre corrientes de escaso caudal (7):

$$
E=\alpha(1+\sqrt{a})
$$

Donde a es un coeficiente que oscila entre 0,16 a o,20, y a es la luz. Por ello, el espesor de la clave a partir de una luz de $5 \mathrm{~m}$ es:

$$
E=0,20(1+\sqrt{5})=0,648 m
$$

Tres de los puentes de la línea -Ribera de Gata, Árrago y Águeda 2- son similares entre sí (figura 10). Al igual que el ya descrito sobre el Águeda, se componían de un tramo central metálico y dos vanos laterales de hormigón revestido. En este caso, la celosía Pratt alcanza los $20 \mathrm{~m}$ de largo para salvar una luz de 17 $\mathrm{m}$, el canto es de $2 \mathrm{~m}$ y los montantes están dispuestos cada 2,5 $\mathrm{m}$. La anchura es similar, de $4 \mathrm{~m}$, con dos pasarelas laterales; una diferencia con respecto al Águeda 1 es que los cuchillos se arriostran en el plano inferior mediante cruces de San Andrés. En cuanto a los arcos laterales, presentan luces de $5 \mathrm{~m}$ los del Árrago y Ribera de Gata), y $10 \mathrm{~m}$ el Águeda 2. En este último caso, el espesor de la clave es de $0,80 \mathrm{~m}$.

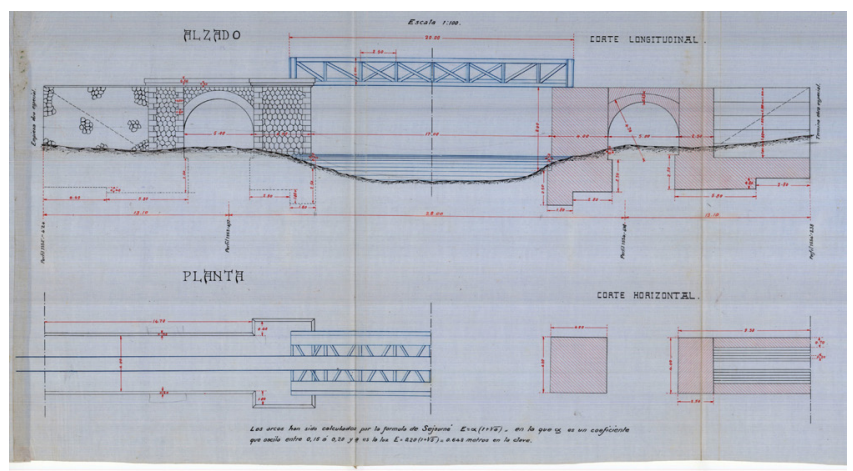

Figura 10. Puente sobre el río Ribera de Gata

El viaducto sobre el río Acebo (figura 11) es el de mayor longitud: $335 \mathrm{~m}$. La margen Oeste comprende cuatro dinteles biapoyados de $15 \mathrm{~m}$ de luz cada uno y $3 \mathrm{~m}$ de anchura sobre pilas que alcanzan 37,20 $\mathrm{m}$ de altura máxima; además, en planta forma una curva de $120 \mathrm{~m}$ de radio. En la margen Este se proyectan siete vanos similares a los citado de la margen 
Tabla 8. Estructuras y túneles

\begin{tabular}{|c|c|c|c|}
\hline \multicolumn{4}{|c|}{ Estructuras principales } \\
\hline Nombre & PK & $\begin{array}{c}\text { Coste } \\
\text { (pesetas) }\end{array}$ & $\begin{array}{c}\text { Descripción (luces } \\
\text { de cada tramo) }\end{array}$ \\
\hline Águeda 1 & $5+730$ & $223.194,22$ & $\begin{array}{l}\text { Un tramo metálico de } \\
60 \mathrm{~m} \text { y dos arcos de } 5 \mathrm{~m}\end{array}$ \\
\hline Águeda 2 & $47+428$ & $157.902,40$ & $\begin{array}{l}\text { Un tramo metálico de } 20 \\
\mathrm{~m} \text { y dos arcos de } 10 \mathrm{~m}\end{array}$ \\
\hline Acebo & $74+866$ & $1.200 .000,00$ & $\begin{array}{l}\text { Hormigón armado. } 3 \text { ar- } \\
\text { cos de } 45 \mathrm{~m} \text { y } 11 \text { tramos } \\
\text { de } 15 \mathrm{~m}\end{array}$ \\
\hline $\begin{array}{l}\text { Ribera de } \\
\text { Gata }\end{array}$ & $109+598$ & $103.639,03$ & $\begin{array}{l}\text { Un tramo metálico de } 20 \\
\mathrm{~m} \text { y dos arcos de } 5 \mathrm{~m}\end{array}$ \\
\hline Árrago & $114+796$ & $102.549,67$ & $\begin{array}{l}\text { Un tramo metálico de } 20 \\
\mathrm{~m} \text { y dos arcos de } 5 \mathrm{~m}\end{array}$ \\
\hline Alagón & $129+457$ & 275.000,00 & $\begin{array}{l}\text { Hormigón armado, tres } \\
\text { tramos de } 25 \mathrm{~m}\end{array}$ \\
\hline Guadalcín & $164+734$ & $500.935,93$ & $\begin{array}{l}\text { Un tramo metálico de } \\
60 \mathrm{~m}\end{array}$ \\
\hline \multicolumn{4}{|c|}{ Túneles } \\
\hline \multicolumn{2}{|c|}{ Definición } & PK & Coste (pesetas) \\
\hline \multicolumn{2}{|c|}{ Túnel de $485 \mathrm{~m}$} & $66+222,50$ & $435 \cdot 416,50$ \\
\hline \multicolumn{2}{|c|}{ Túnel de 70,86 m } & $66+733,43$ & $84.157,03$ \\
\hline \multicolumn{2}{|c|}{ Túnel de 211,12 m } & $69+069,44$ & $204.192,66$ \\
\hline
\end{tabular}

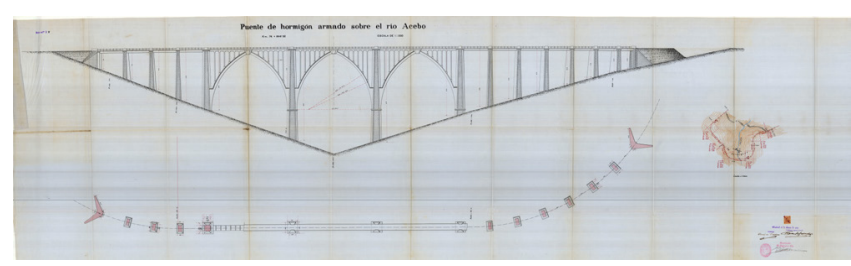

Figura 11. Viaducto sobre el río Acebo

Oeste, que también desarrollan un tramo en curva de $120 \mathrm{~m}$ de radio. La parte central se resuelve mediante tres vanos de $45 \mathrm{~m}$ de luz y altura máxima de 57,50 m; cada uno de ellos comprende dos semiarcos apuntados de $38 \mathrm{~m}$ de radio y 1,5 $\mathrm{m}$ de canto que se unen en la clave; hay montantes cada $3 \mathrm{~m}$ uniendo el citado arco con el tablero, cuyo canto es de aproximadamente $2 \mathrm{~m}$.

El paso sobre el río Alagón se resuelve mediante otro puente notable (figura 12). Se trata de una estructura de tres vanos de celosía de hormigón armado de $25 \mathrm{~m}$ de luz, de pila a pila. Este puente fue encargado a José Eugenio Ribera, quizá el ingeniero estructural más reputado en la España de la época. Ribera era un gran defensor del hormigón armado y había realizado ya varios puentes notables con ese material en España. Las ventajas de la celosía de hormigón, fundamentalmente, radicaban en la mejor conservación que éste tenía frente al acero. El nombre dado a esta tipología en el proyecto es "puente de hierro hormigonado", definida así por el propio Ribera en su libro Puentes de fábrica y hormigón armado (8):

Hierro hormigonado.- Se aplica este nombre cuando las armaduras metálicas están constituidas por viguetas del comercio o vigas armadas que resisten, por sí solas, todos los esfuerzos, y en las que el hormigón que las envuelve sólo desempeña un papel de preservativo del hierro contra la oxidación o el fuego.
Los tramos miden 26,50 m de largo y 2,60 m de canto, y dejan una altura libre máxima de $6,80 \mathrm{~m}$. El tablero consiste en sendos cuchillos de celosía tipo Pratt separados $2 \mathrm{~m}$, arriostrados mediante vigas horizontales dispuestas cada 2,30 m; la anchura de los cuchillos es de 0,35 m. Aclaramos que los planos no abundan en detalles, y las medidas aquí expuestas se obtienen midiendo sobre los propios planos aplicando la escala. Posiblemente, Govantes acordaría con Ribera encargarle el proyecto y este último tendría en su propio gabinete la información detallada del mismo. O quizá los planos reflejan únicamente unas dimensiones estándar que luego serían definidas en un proyecto que se realizaría tras la obtención de la concesión de la línea. El puente es similar a otros apuntados por Ribera en su libro, citado anteriormente: el de Alfonso XIII sobre el río Lucus en Larache, construido en 1929 y proyectado por el ingeniero Pascual Aragonés (9); el puente de Serradilla sobre el Tajo, proyectado por el ingeniero Enrique Colás Arias y finalizado en 1929 (10); o una serie de puentes para los Ferrocarriles Suburbanos de Málaga proyectados en 1907 por Juan Manuel de Zafra (11).

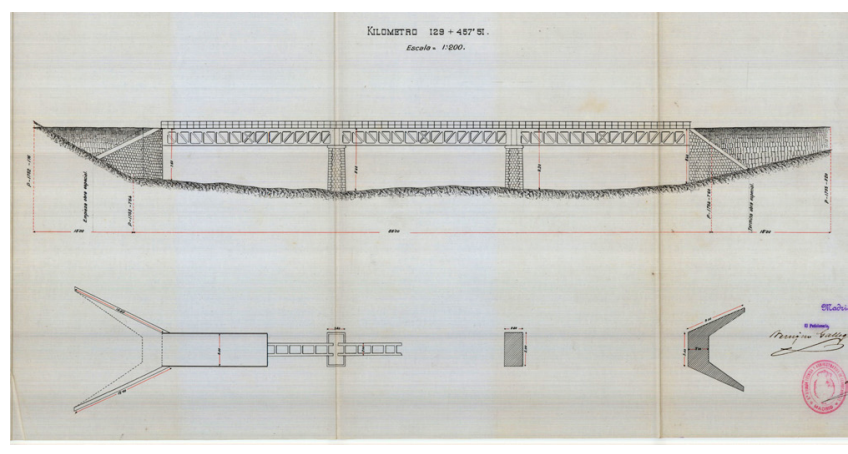

Figura 12. Puente de Ribera sobre el río Alagón

Por último, el puente sobre el Guadalcín (figura 13) ofrece una tipología estructural diferente a las citadas anteriormente. En este caso, se propone un arco metálico rebajado de $60 \mathrm{~m}$ de luz y flecha $6 \mathrm{~m}$. El arco conforma una celosía Pratt de $4 \mathrm{~m}$ de ancho con montantes cada $5 \mathrm{~m}$. Los cuchillos se arriostran perpendicularmente, paralelos a los montantes, mediante cruces de San Andrés. Es destacable que la estructura incluye una rótula en el centro, por lo que el puente está formado por dos semiarcos. En relación con los estribos, sabemos que la cimentación se proyecta con hormigón hidráulico. El resguardo es de $15 \mathrm{~m}$ entre el nivel de aguas medias y el arranque de la estructura metálica.

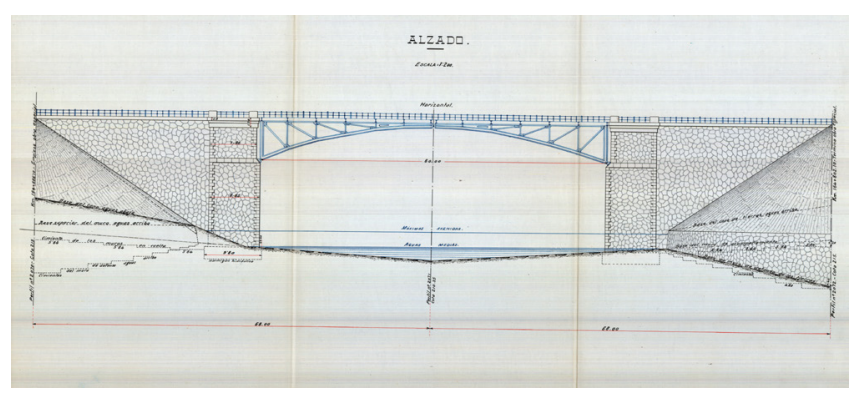

Figura 13. Puente sobre el río Guadalcín

\section{ESTACIONES}

El proyecto incluye la descripción de los edificios necesarios para la explotación: estaciones de tres clases, talleres, cocheras, casillas de guarda o depósitos de agua. En Ciu- 
dad Rodrigo, además del edificio de viajeros y retretes, se prevé construir un muelle cubierto y otro descubierto, una cochera para 10 locomotoras (recordemos que el total de locomotoras previstas era 15), otra para carruajes, depósitos de carbón y agua, una grúa fija y una báscula o talleres; todo ello ocupa una superficie de $24 \cdot 317,55 \mathrm{~m}^{2}$. La de Río Tajo incluye unos muelles de transbordo pero carece de talleres, y su superficie asciende a $25.255 \mathrm{~m}^{2}$. Por su parte, las estaciones menores se proyectan con un menor número de edificios y con andenes más cortos que los de las estaciones extremas (tablas 9 y 10).

Tabla 9.

\begin{tabular}{|l|c|c|l|}
\hline Tipología & Cantidad & $\begin{array}{c}\text { Longitud entre } \\
\text { agujas extremas }\end{array}$ & \multicolumn{1}{|c|}{ No de vías $^{\text {a }}$} \\
\hline $\begin{array}{l}\text { Estaciones } \\
\text { de empalme }\end{array}$ & 2 & $300 \mathrm{~m}$ & Variable \\
\hline $1^{\mathrm{a}}$ clase & 2 & $300 \mathrm{~m}$ & $\begin{array}{l}\text { 4 vías de enlace } \\
\text { y } 2 \text { muertas }\end{array}$ \\
\hline $2^{\mathrm{a}}$ clase & 8 & $250 \mathrm{~m}$ & $\begin{array}{l}\text { 2 vías de enlace } \\
\text { y } 1 \text { muerta }\end{array}$ \\
\hline $3^{\mathrm{a}}$ clase & 3 & $200 \mathrm{~m}$ & 3 vías de enlace \\
\hline
\end{tabular}

En cuanto a distribución de vías, se procura que las vías en las estaciones se dispongan rectas y con rasante horizontal. La entrevía se plantea de $3 \mathrm{~m}$, y los aparatos de vía se proyectan con radios de curva de $100 \mathrm{~m}$.

Uno de los elementos relevantes es la propuesta de construir vías de triple carril, solución que permite la circulación de los trenes de ancho métrico a la estación previa y a sus muelles (figura 14). Para ello se añade un carril adicional entre los dos ya construidos, de ancho ibérico, correspondientes a las estaciones originales. Esta solución, existente en otros países ya en el siglo XIX, era menos habitual en España, y aquí se propone para poder hacer la descarga por tope directamente de vagón a vagón.

En cuanto a los edificios principales, se proponen tres clases de estaciones; además, las de Ciudad Rodrigo y Río Tajo (figura 15) son estaciones de empalme, con edificios de primera clase. Todos los edificios constan de dos plantas, con servicios para los pasajeros en la planta baja y vivienda para empleados en la primera. Los retretes, "amplios y ventilados" según leemos, con "separación de señoras y caballeros", se sitúan en el exterior de los edificios. El edificio de primera clase, de 31,70 x 9,00 m, incluye vestíbulo, una sala de espera para viajeros de primera clase y otra para los de segunda, despacho del jefe de estación, despacho para expedición de billetes y oficinas, archivo, lampistería y restaurante; la vivienda de la primera planta comprende cuatro dormitorios, sala y comedor en un total de $89 \mathrm{~m}^{2}$ (figura 16). Por su parte, los edificios de segunda y tercera clase son más pequeños y carecen de restaurante $\mathrm{o}$ archivo.

Unos edificios habituales en estos proyectos son las casillas de guarda, que se ubicaban en los cruces con los caminos preexistentes, y que uniformizaban la presencia del ferrocarril en el territorio atravesado. En este caso se proyectan 54 casillas, 30 en la primera sección y 24 en la segunda, cuyo coste unitario es de 5.623,56 pesetas. Consisten en edificaciones pequeñas de $48 \mathrm{~m}^{2}$ de planta, con tres habitaciones y un desván abuhardillado.
Tabla 1o. Edificios y coste de las estaciones. Leyenda: Edificio viajeros (EV), muelle cubierto (MC), muelle descubierto (MD), Cochera locomotoras (CL), Cochera carruajes (CC), Depósito de carbón (DC), Depósito de agua (DA), Retretes (R), Grúa fija (GF), Báscula material móvil (B), Talleres (T), Muelle de transbordo Cubierto (MTC), Muelle de transbordo descubierto (MTD)

\begin{tabular}{|c|c|c|}
\hline Estación y clase & $\begin{array}{c}\text { Coste } \\
\text { (pesetas) }\end{array}$ & Instalaciones \\
\hline $\begin{array}{l}\text { Ciudad Rodrigo } \\
\left(1^{\mathrm{a}}, \text { empalme }\right)\end{array}$ & $247.652,76$ & $\begin{array}{l}\text { EV, MC, MD, CL 1o puestos, } \\
\text { CC, DC, DA, R, GF, B, T, } \\
\text { andén } 100 \text { m }\end{array}$ \\
\hline Fresno $\left(3^{a}\right)$ & $40.010,76$ & $\mathrm{EV}, \mathrm{MD}, \mathrm{R}$, andén $50 \mathrm{~m}$ \\
\hline Bodón $\left(2^{a}\right)$ & $59.221,48$ & $\begin{array}{l}\mathrm{EV}, \mathrm{MC}, \mathrm{MD}, \mathrm{DA}, \mathrm{R}, \mathrm{B} \text {, andén } \\
60 \mathrm{~m}\end{array}$ \\
\hline $\begin{array}{l}\text { Fuenteguinaldo } \\
\left(2^{\mathrm{a}}\right)\end{array}$ & $59.221,48$ & $\begin{array}{l}\mathrm{EV}, \mathrm{MC}, \mathrm{MD}, \mathrm{DA}, \mathrm{R}, \mathrm{B} \text {, andén } \\
60 \mathrm{~m}\end{array}$ \\
\hline Peñaparda $\left(2^{\mathrm{a}}\right)$ & $59.221,48$ & $\begin{array}{l}\mathrm{EV}, \mathrm{MC}, \mathrm{MD}, \mathrm{DA}, \mathrm{R}, \mathrm{B} \text {, andén } \\
60 \mathrm{~m}\end{array}$ \\
\hline Payo $\left(2^{\mathrm{a}}\right)$ & $59.221,48$ & $\begin{array}{l}\mathrm{EV}, \mathrm{MC}, \mathrm{MD}, \mathrm{DA}, \mathrm{R}, \mathrm{B} \text {, andén } \\
60 \mathrm{~m}\end{array}$ \\
\hline Acebo $\left(3^{a}\right)$ & $40.010,76$ & $\mathrm{EV}, \mathrm{MD}, \mathrm{R}$, andén $50 \mathrm{~m}$ \\
\hline Hoyos $\left(1^{a}\right)$ & $134.003,03$ & $\begin{array}{l}\mathrm{EV}, \mathrm{MC}, \mathrm{MD}, \mathrm{CL} 2 \text { puestos, } \\
\mathrm{CC}, \mathrm{DC}, \mathrm{DA}, \mathrm{R}, \mathrm{GF}, \mathrm{B} \text {, andén } \\
80 \mathrm{~m}\end{array}$ \\
\hline Perales $\left(2^{a}\right)$ & $59.221,48$ & $\begin{array}{l}\mathrm{EV}, \mathrm{MC}, \mathrm{MD}, \mathrm{DA}, \mathrm{R}, \mathrm{B} \text {, andén } \\
60 \mathrm{~m}\end{array}$ \\
\hline Moraleja $\left(2^{a}\right)$ & $59.221,48$ & $\begin{array}{l}\mathrm{EV}, \mathrm{MC}, \mathrm{MD}, \mathrm{DA}, \mathrm{R}, \mathrm{B} \text {, andén } \\
60 \mathrm{~m}\end{array}$ \\
\hline Don Gómez $\left(3^{\mathrm{a}}\right)$ & $40.010,76$ & $\mathrm{EV}, \mathrm{MD}, \mathrm{R}$, andén $50 \mathrm{~m}$ \\
\hline $\operatorname{Coria}\left(1^{a}\right)$ & $134.003,03$ & $\begin{array}{l}\mathrm{EV}, \mathrm{MC}, \mathrm{MD}, \mathrm{CL} 2 \text { locomo- } \\
\text { toras, CC, DC, DA, R, GF, B, } \\
\text { andén } 80 \mathrm{~m}\end{array}$ \\
\hline Torrejoncillo $\left(2^{\mathrm{a}}\right)$ & $59.221,48$ & $\begin{array}{l}\mathrm{EV}, \mathrm{MC}, \mathrm{MD}, \mathrm{DA}, \mathrm{R}, \mathrm{B} \text {, andén } \\
60 \mathrm{~m}\end{array}$ \\
\hline Portezuelo $\left(2^{\mathrm{a}}\right)$ & $59.221,48$ & $\begin{array}{l}\mathrm{EV}, \mathrm{MC}, \mathrm{MD}, \mathrm{DA}, \mathrm{R}, \mathrm{B} \text {, andén } \\
60 \mathrm{~m}\end{array}$ \\
\hline $\begin{array}{l}\text { Río Tajo (1 }{ }^{\mathrm{a}} \\
\text { empalme) }\end{array}$ & $208.404,46$ & $\begin{array}{l}\text { EV, MC, MD, CL 1o puestos, } \\
\text { CC, DC, DA, R, GF, B, andén } \\
80 \text { m, MTC, MTD }\end{array}$ \\
\hline
\end{tabular}

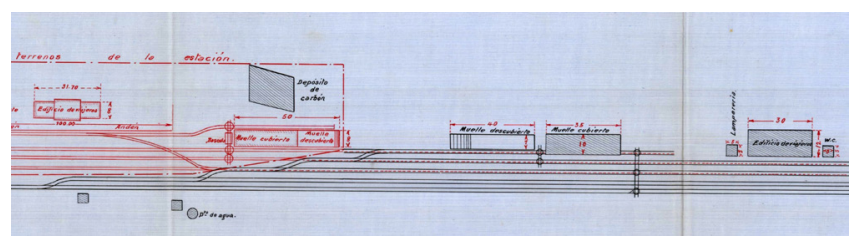

Figura 14. Detalle estación de CR, con el tercer carril trazado en línea discontinua entre los carriles preexistentes

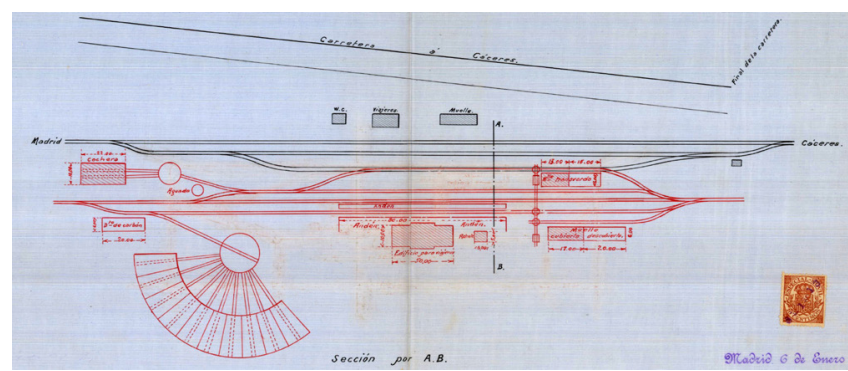

Figura 15. Estación de empalme en Río Tajo. La vía existente, Madrid-Cáceres, se representa en negro; las nuevas instalaciones se representan en rojo. Puede observarse el conjunto de cocheras para locomotoras en la parte inferior, formando un abanico 


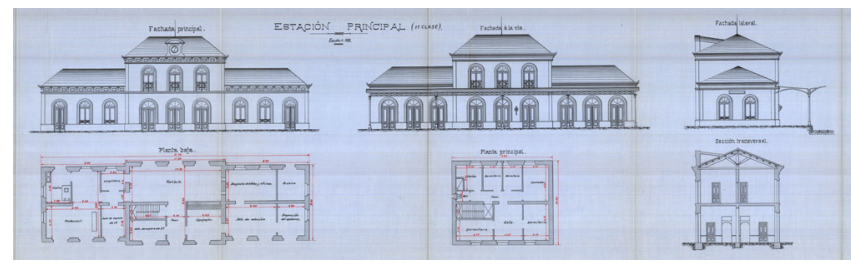

Figura 16. Edificio de estación de primera clase

Otro edificio singular es la cochera de locomotoras (figura 17). El proyecto describe una edificación que podía albergar dos locomotoras junto a una plataforma móvil que permite orientar la vía hacia cualquiera de las dos ubicaciones previstas. La anchura mínima del espacio para una locomotora es de 5,25 $\mathrm{m}$ y su longitud alcanza los $20 \mathrm{~m}$. La cubierta del edificio consiste en una cercha que permite un gálibo máximo de 4,08 m. En las estaciones de primera clase se prevé un edificio de este tipo para dos locomotoras; además, en las estaciones de cabecera se proyectan cinco edificios de este tipo colindantes conformando una suerte de abanico para albergar un total de diez locomotoras.

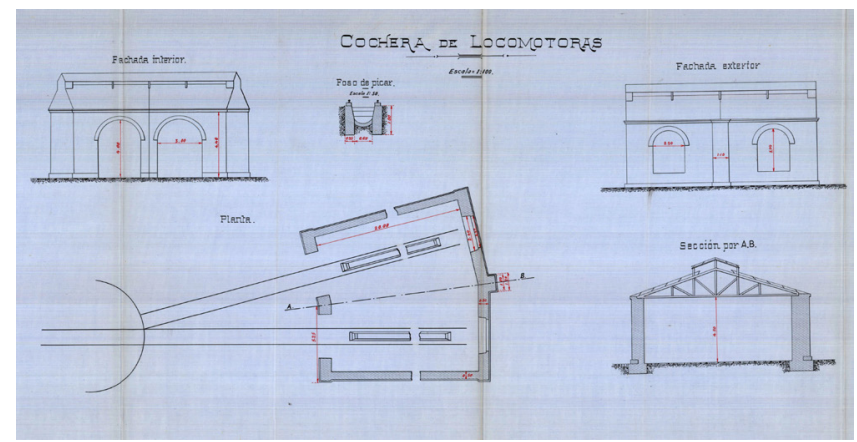

Figura 17. Cochera de locomotoras

Una edificación notable es el depósito de agua, elemento fundamental para el funcionamiento de las locomotoras que se repartiría a lo largo de la traza, junto a las estaciones de primera y segunda clase (figura 18). Podía contener un total de $25 \mathrm{~m}^{3}$, y su altura total era de $8 \mathrm{~m}, 6 \mathrm{~m}$ la parte de mampostería y $2 \mathrm{~m}$ la parte metálica. El interior, hueco, incluye dos bóvedas para soportar el peso del depósito cargado.

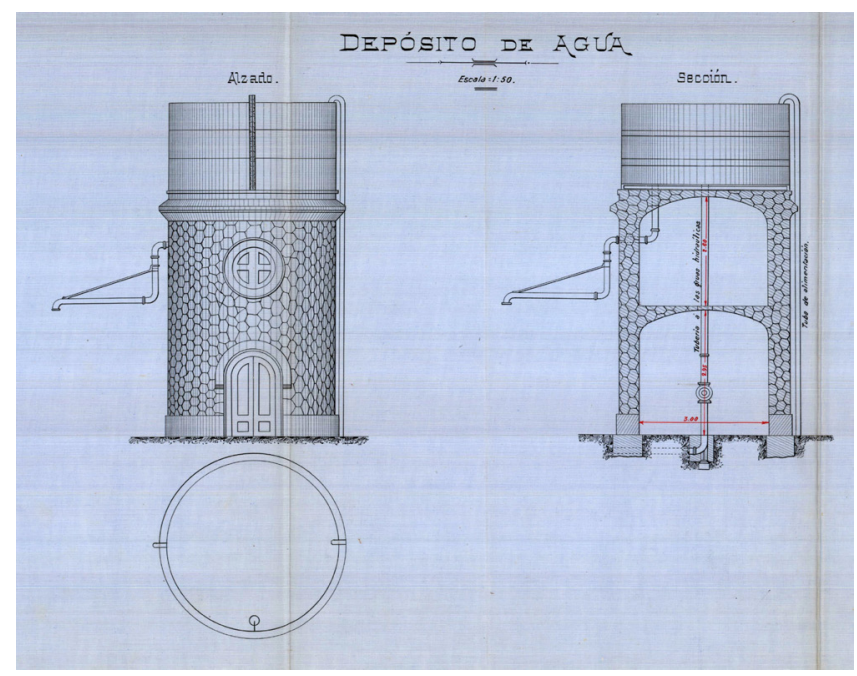

Figura 18. Depósito de agua

\section{LA MODIFICACIÓN DE FELICIANO NAVARRO}

Como señalábamos en otro apartado, el ingeniero del Ministerio Feliciano Navarro realizó una serie de cambios en el proyecto original (AGA 24-08965), en un documento firmado el 17 de noviembre de 1916. Navarro altera el trazado acortándolo en $6.500 \mathrm{~m}$, modifica el perfil longitudinal y cambia el punto de paso sobre el Acebo, sustituyendo además el viaducto de hormigón armado por dos estructuras menores.

Los cambios afectaban también al presupuesto, proponiendo rebajar varias de las estimaciones de Govantes en medición y en precios unitarios. Gracias a ellas los costes de expropiación disminuyen en un $20 \%$; los de movimiento de tierras se reducen para hacerlos similares a los de otros proyectos recientes (La Carolina a Puertollano, en este caso); la sección de túnel se reduce de los $30 \mathrm{~m}^{2}$ de sección a la empleada en el ferrocarril de Andoáin a Plazaola, una línea con numerosos túneles (12); finalmente el presupuesto para las estaciones queda mermado, aunque no aparecen datos de los nuevos edificios propuestos. El coste total del proyecto ferroviario pasa de las $35 \cdot 322.430,54$ pesetas originales a $25.311 .465,78$ pesetas. En cuanto a los ingresos, Navarro considera que el tráfico previsto por Govantes es exagerado: el proyecto original estima que el ingreso kilométrico puede establecerse en $\mathbf{2 2 . 8 9 4 , 7 0}$ pesetas por km y año; sin embargo, la línea de Cáceres y Portugal había tenido ingresos de 15.00o pesetas y la de Salamanca a la Frontera portuguesa lo había tenido de 6.000 pesetas. Navarro considera, por ello, que la cifra de 10.000 pesetas es más realista.

\section{CONCLUSIONES}

La investigación realizada pone de relieve la importancia de los proyectos no construidos como fuentes del estado del arte de la ingeniería de caminos: se han obtenido datos sobre aspectos como la planificación de las obra, las estructuras y estaciones, los criterios en explanaciones y desmontes, los costes de los materiales y de los jornales, y también nos ha permitido recabar datos sobre el estado social y económico del territorio donde se inserta la línea. Los datos se refieren además a un ferrocarril de ancho métrico, que en un momento dado llegaron a suponer más del $27 \%$ de las líneas ferroviarias españolas (13). Al hilo de esta conclusión, apuntamos que estos proyectos forman parte del patrimonio de la ingeniería de caminos en España, que no sólo está formado por los proyectos construidos sino también por otros muchos documentos técnicos históricos.

En relación con las estructuras, el proyecto refleja una época donde el hierro y el acero comenzaban a dar paso a otros materiales y formas (14). La viga triangulada protagonizó las grandes estructuras ferroviarias desde los años 1840, y en España hacia 1880 encontramos ya un análisis interesante sobre la idoneidad de cada tipo de celosía (15). Los grandes puentes ferroviarios españoles rara vez presentaban vanos mayores a $60 \mathrm{~m}$ (69 m en Tuy; 60,5 m Ormáiztegui), longitud de los puentes Águeda 1 y Guadalcín. Intuimos que la diferencia en tipología entre ambos (Águeda 1 es viga, Guadalcín es arco) radica en la distinta orografía de los enclaves: la amplia llanura de inundación del Águeda (figura 19), permitiría el montaje de la estructura al pie de la misma y el posterior izado con grúas a la posición definitiva. El Guadalcín presentaba una ribera más abrupta, y se optó por una tipología más compleja en 


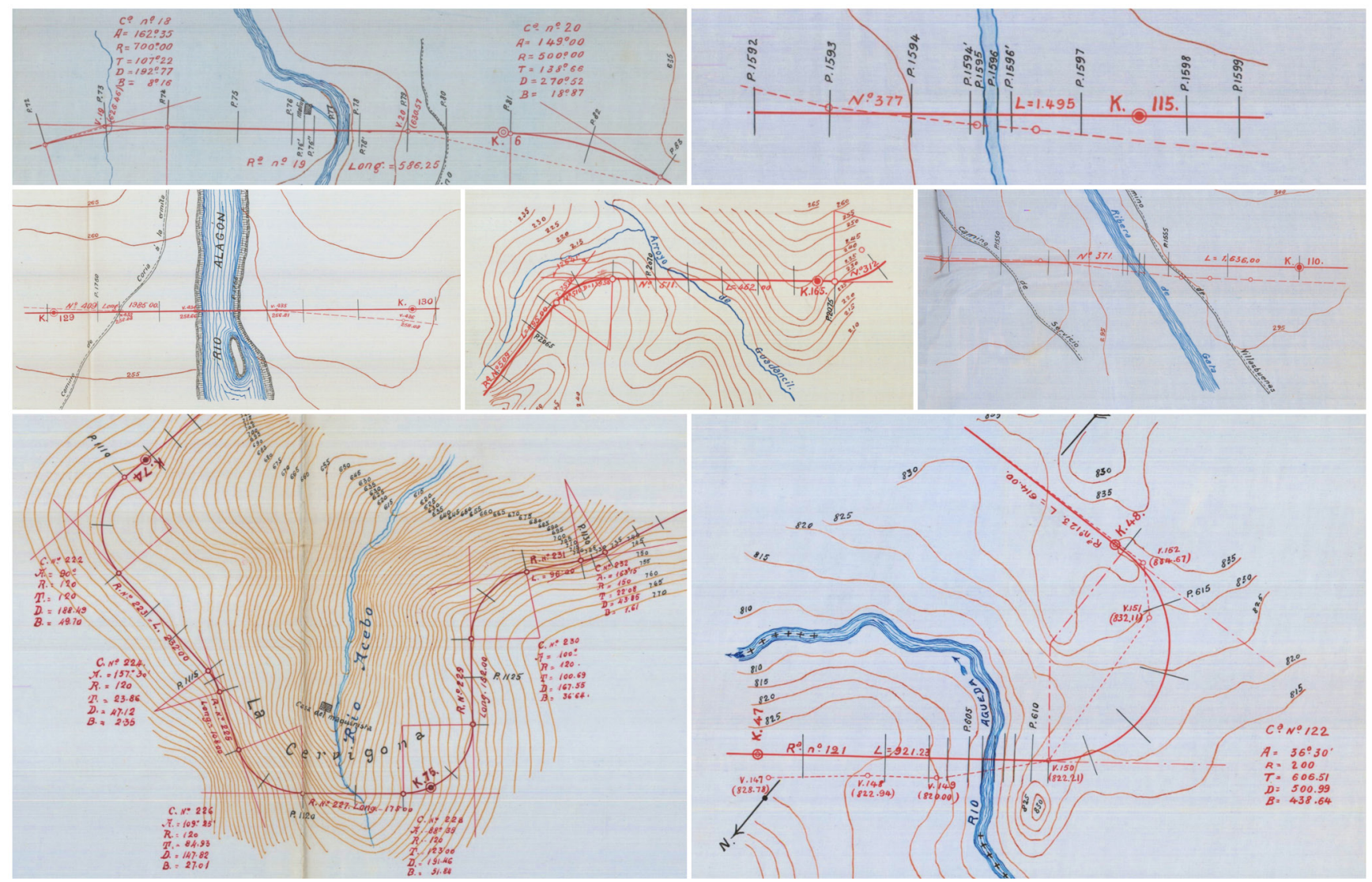

Figura 19. Detalle de los entornos de los puentes. De izquierda a derecha, y de arriba abajo: Águeda 1; Árrago; Alagón; Guadalcín; Ribera de Gata; Acebo; y Águeda 2

cuanto a lo estructural que exigía un montaje por avance en ménsula más complejo.

El hormigón armado, por su parte, comenzó a ser empleado en los viaductos carreteros y ferroviarios a finales del siglo XIX y hacia 1930 se había erigido como el material más utilizado en las grandes estructuras. En este proyecto se intuye ya esa evolución, pues el viaducto principal de la línea, el Acebo, se proponía ya con hormigón armado. La presencia del otro puente de hormigón, el del Alagón, sorprende porque en el proyecto hay estructuras trianguladas metálicas de mayor y menor luz, y quizá lo lógico sería que todas las estructuras de ese rango de luces tuviesen una misma tipología. Pensamos que su inclusión puede deberse a un intento de añadir valor a la propuesta presentada para la licitación de la línea al ir firmado por Ribera.

Por último, en lo concerniente a las estructuras, pensamos que Ribera estuvo también involucrado en el proyecto del Acebo pese a que en el proyecto sólo es citado en tanto que autor del puente de hierro hormigonado (además, en singular). Algunos detalles muestran similitudes entre ambas estructuras: en ninguna de las dos representaciones en alzado (figuras 11 y 12) se nos muestra el río, como si el autor desconociera tal detalle o no lo representara habitualmente; los estribos incluyen aletas que se abren -a diferencia de los otros puentes del proyecto-; el presupuesto de ambos carece de descompuesto y queda fijado en una cantidad redonda (tabla 9); finalmente, no hay cálculos de ambas estructuras (aunque quizá el proyecto consultado no estuviera completo en el archivo). También resaltamos la similitud entre el viaducto del Acebo y el posterior puente de Gaznata, proyectado por Ribera hacia 1918.
Podemos aludir también al paisaje que no llegó a existir, pues el impacto paisajístico de la línea en las comarcas atravesadas habría sido notable, y muy especialmente el de los siete grandes puentes proyectados. Asimismo, el cuidado mostrado en el diseño de los edificios nos relaciona con la importancia de estas arquitecturas en el contexto de unas poblaciones de carácter rural; el caso de la estación proyectada de Río Tajo habría sido sorprendente en cuanto a su importancia paisajística, al situarse alejada de cualquier población.

Una conclusión que emerge tras la lectura del proyecto es comprobar la enorme cantidad de referencias que se realizan a otros proyectos ferroviarios de la época para comparar precios, estimar rentabilidades, predimensionar estructuras, etc. En ese momento no había bases de precios, pero sí una gran cantidad de proyectos que se llevaban a cabo, y éstos eran usados como referencia. También aparecen citas a proyectos de otros países, notablemente de Francia, que es tomado como país puntero en cuanto a desarrollo ferroviario.

Otra de las conclusiones nos lleva a la planificación de infraestructuras en la década de 1910. En la Memoria se leen reflexiones sobre el ferrocarril como objetivo de primer orden desde el punto de vista bélico, y de su importancia para la defensa nacional, y el proyecto es ejemplo de la red de ferrocarriles secundarios y estratégicos planificados en Extremadura, que nunca llegó a construirse. Sin duda, esta red hubiera supuesto un importante revulsivo económico para las comarcas atravesadas, cuyo carácter fronterizo ha 
limitado el desarrollo de unas infraestructuras de transporte eficaces. Este ferrocarril hubiera supuesto, además, que enclaves como Coria ( $5^{\mathrm{a}}$ población de la provincia actualmente) o Moraleja ( $8^{\mathrm{a}}$ población de la provincia) tuviesen ferrocarril. Debemos reconocer que los ferrocarriles secundarios construidos en otras zonas peninsulares fueron puestos en cuestión ya en la década de 1920 por su escasa competitividad frente al automóvil, que se estaba expandiendo con fuerza (16), pero el abandono de los proyectos de ferrocarril secundario en Extremadura es muestra también de la tradicional desidia de las administraciones hacia esta región.

\section{AGRADECIMIENTOS}

La investigación se ha realizado con el apoyo del proyecto nacional de investigación "Análisis y definición de estrategias para la caracterización, recuperación y puesta en valor del patrimonio de las obras públicas. Una aproximación desde la escala territorial" (PID2019-105877RA-100).

Parte de la investigación se realizó durante una estancia de investigación en la Sapienza Università di Roma en 2019. El autor agradece especialmente la colaboración de la profesora Maria Martone durante la misma.

\section{REFERENCIAS / REFERENCES}

(1) Peris Torner, J. (2015). Sociedad Extremeño Castellana (Ferrocarril de Ciudad Rodrigo al Rio Tajo). Consultado 12 octubre 2020, en Spanish Railway: www.spanishrailway.com/sociedad-extremeno-castellana/

(2) Cambó, F. de A. (1918a). Ferrocarriles secundarios: legislación y estadística de los pequeños ferrocarriles en el extranjero. Revista de Obras Públicas, 66(1), 560-563.

(3) Cambó, F. de A. (1918b). Ferrocarriles secundarios y estratégicos: características fundamentales de las legislaciones españolas y extranjeras. Revista de Obras Públicas, 66(1), 577-583.

(4) Álvarez Mántaras, D., \& Luque Rodríguez, P. (2003). Ferrocarriles. Ingeniería e Infraestructura de los Transportes. Oviedo: Universidad de Oviedo.

(5) Plasencia-Lozano, P. (2019). La impronta del ferrocarril Peñarroya-Fuente del Arco en el territorio, como ejemplo de paisaje modificado por la ingeniería. Norba, Revista de Arte, 39, 85-108. https://doi.org/10.17398/2660-714X.39.85

(6) Martínez Méndez, P. (1990). Nuevos datos sobre la evolución de la peseta entre 1900 y 1936. Información complementaria. Retrieved March 3, 2020, from Banco de España. Servicio de Estudios. Documento de trabajo 9011 website: https://www.bde.es/f/webbde/SES/Secciones/Publicaciones/PublicacionesSeriadas/DocumentosTrabajo/90/Fich/ dt_9011.pdf

(7) Villalba Granda, C. (1933). El puente sobre el río Guadiana en Villanueva de la Serena. Revista de Obras Públicas, 81(1).

(8) Ribera, J. E. (1934). Puentes de fábrica y hormigón armado: tomo 1. Madrid: Talleres Gráficos Herrera.

(9) García Augustín, J. (1929). Puente de Alfonso XIII, sobre el Luccus, en Larache. Revista de Obras Públicas, 77(1), 49-54.

(10) Arévalo Hernández, E. M. (2013). El puente de Serradilla. Consultado 3 marzo 2020, en Las carreteras de Extremadura: lascarreterasdeextremadura.blogspot.com/2013/12/el-puente-de-serradilla.html

(11) Burgos Núñez, A. (2019). J.M. de Zafra y los orígenes de los puentes de vigas trianguladas de hormigón armado en España. Informes de La Construcción, 71(553), 283. https://doi.org/10.3989/ic.70538

(12) Gallego, M. (1914). El nuevo ferrocarril de Pamplona a San Sebastian. La Construcción Moderna, 16, $241-245$.

(13) Morillas-Torné, M. (2014). El ferrocarril de vía estrecha en España, 1852-2010. El papel de la intermodalidad y de la demanda en su construcción y estado actual. Scripta Nova. Revista Electrónica de Geografía y Ciencias Sociales, 18(485).

(14) Aguiló, M. (2008). Forma y tipo en el arte de construir puentes. Madrid: Abada.

(15) Anon. (1880). Los puentes de fundición comparados con los de hierro forjado. Revista de Obras Públicas, 28, $236-239$.

(16) Aguilar López, M. (1924). Utilidad de los ferrocarriles secundarios. Revista de Obras Públicas, 72(1), $101-104$. 